\title{
Preparation of a Nanobody Specific to Dectin I and Its Anti-inflammatory Effects on Fungal Keratitis
}

\author{
Xing Liu', Jianxin Sui ${ }^{2}$, Cui Li', Xudong Peng', Qian Wang', Nan Jiang', Qiang Xu', Luokai Wang², \\ Jing Lin', Guiqiu Zhao' \\ 'Department of Ophthalmology, Affiliated Hospital of Qingdao University, Qingdao, People's Republic of China; ${ }^{2}$ College of Food Science and \\ Engineering, Ocean University of China, Qingdao, People's Republic of China
}

Correspondence: Jing Lin; Guiqiu Zhao, Department of Ophthalmology, Affiliated Hospital of Qingdao University, 16 Jiangsu Road, Qingdao 266003, Shandong, People's Republic of China, Email linjing_yk@I26.com; zhaoguiqiu_good@126.com

Objective: To prepare a nanobody specific to dectin 1 and verify its specificity and anti-inflammatory effects on Aspergillus fumigatus keratitis.

Methods: The nanobody was selected from a high-quality shark-antibody library constructed with phage-display technology. The nanobody was developed in the expression systems of Escherichia coli. Indirect ELISA was used to determine the specificity of the nanobody to recombinant dectin 1 protein. The potential of the nanobody to be recognized and expressed on the surfaces of cells and corneas was detected by immunofluorescence, and its anti-inflammatory effect on A. fumigatus keratitis was further verified. After infection with A. fumigatus, eyes of C57B L/6 mice were treated with nanobodies. Human corneal epithelial cells (HCECs) were pretreated with nanobodies and then incubated with A. fumigatus. Clinical scores and slit-lamp photography were used to assess disease response in mouse corneas. RT-PCR and ELISA were used to evaluate mRNA and protein expression of IL1 $\beta$ and IL6 in both mouse corneas and HCECs.

Results: The nanobody was successfully expressed through microbial system and showed specific high-affinity binding to recombinant dectin 1. Furthermore, it exhibited specific binding to dectin 1 expressed on the surfaces of cells and recognized dectin 1 in mouse corneas. Importantly, it reduced clinical scores of A. fumigatus keratitis in mice compared with a PBS-treatment group. In addition, it decreased mRNA and protein expression of IL1 $\beta$ and IL6 in infected corneas and HCECs stimulated with A. fumigatus. Conclusion: These results suggest that this nanobody can bring about anti-inflammatory effects. This highlights the potential of these nanobodies as innovative therapeutic agents in A. fumigatus.

Keywords: nanobody, Aspergillus fumigatus, dectin 1, inflammation, cornea

\section{Introduction}

Fungal keratitis is a severe blinding eye infection caused by pathogenic fungi and has a high incidence in developing countries. ${ }^{1-4}$ Corneal trauma due to vegetative material provides an opportunity for fungal infection of the cornea. ${ }^{5}$ With the excessive use of broad-spectrum antibiotics, irregular use of glucocorticoids, and wearing of contact lenses, the incidence of fungal keratitis has increased in recent years. ${ }^{6}$ Aspergillus fumigatus is one of the most common pathogenic fungi in fungal keratitis, resulting in inflammatory responses triggered by pattern-recognition receptors (PRRs) of innate immunity. ${ }^{7}$ A significant PRR, dectin 1 participates in inflammatory responses against fungal infection in fungal keratitis. ${ }^{8}$ Although innate immunity plays a significant role in the early stage of fungal infection, it can cause excessive inflammatory reactions. ${ }^{9}$ Excessive inflammatory reactions are detrimental to tissue repair and fungi clearance in fungal keratitis. ${ }^{10,11}$ A recent study has shown that suppression of excessive inflammatory responses may improve prognosis. ${ }^{12}$ Therefore, it is necessary to find a new drug that can act against dectin 1 to relieve the severe inflammatory response in fungal keratitis. 
Nanobodies originate naturally from the sera of camelids and shark species, and are part of the variable region of the heavy chain. ${ }^{13}$ Small proteins with molecular weight of only $15 \mathrm{kDa}$, nanobodies display considerable ability to bind antigens not accessible to conventional antibodies with the long third complementarity determining region (CDR3). ${ }^{14,15}$ They are the smallest antigen-binding fragment that retains affinity and specificity in recognizing antigens. ${ }^{16}$ Nanobodies can be expressed in microorganism systems through genetic engineering technology, which can reduce production costs. ${ }^{17}$ Nanobodies have the advantages of low toxicity, favorable permeability, and high specificity. ${ }^{18}$ Previous studies have shown nanobodies to have promising potential as diagnostic and therapeutic tools in many diseases related to infection and inflammation. ${ }^{19-21}$ However, no study has investigated the application of nanobodies in the treatment of fungal keratitis. In this study, a nanobody specific to dectin 1 was prepared and its recognition by dectin 1 in different models verified. The inhibitory effect of the nanobody on the inflammatory response during A. fumigatus infection was investigated. All the results implied that this nanobody could be used as a new candidate for the treatment of fungal keratitis.

\section{Methods}

\section{Affinity Selection of Phages Specific to Dectin I by Phage Display}

The nanobody (IgNAR V) phage-display library was generously provided by the Ocean University of China (Qingdao, China). Phages were generated by infection of the stock library with the M13K07 helper phage, and three rounds of biopanning were carried out as per standard protocols. ${ }^{22}$ In the first round, an immunotube was coated with $4 \mathrm{~mL}$ recombinant dectin $1\left(100 \mu \mathrm{g} / \mathrm{mL}\right.$ dissolved in PBS) overnight at $4^{\circ} \mathrm{C}$ and then blocked with $4 \mathrm{~mL}$ of MPBS (5\% skimmed-milk powder in PBS) for 2 hours at room temperature. Generated phage particles were added and incubated at room temperature for 1 hour in a vertical rotator and 1 hour without rotation. After being washed ten times with PBS, the bound phages were eluted with $1 \mathrm{~mL} 100 \mathrm{mM}$ TEA for 10 minutes at room temperature and neutralized with $1 \mathrm{M}$ Tris$\mathrm{HCl}(\mathrm{pH}$ 7.4). The phage particles were used to infect Escherichia coli TG1 for the next round of panning. The second and third rounds of biopanning followed the same procedure, except the coating concentration was changed to $10 \mu \mathrm{g} / \mathrm{mL}$ and $1 \mu \mathrm{g} / \mathrm{mL}$, and phages were washed ten times with PBS and ten times with PBST (PBS containing 0.05\% Tween 20).

\section{Isolation of Specific Clone Gene}

Polyclonal phage ELISA was used to monitor the selection of positive phages throughout the biopanning. A 96-well plate was coated with $10 \mu \mathrm{g} / \mathrm{mL}$ recombinant dectin $1(100 \mu \mathrm{L} /$ well $)$ overnight at $4^{\circ} \mathrm{C}$ and blocked with MPBS for 2 hours at room temperature. After being washed three times with PBST, $100 \mu \mathrm{L}$ phages from each round of selection containing approximately $10^{9} \mathrm{CFU} / \mathrm{mL}$ of phage particles was added to the wells and incubated for 1 hour at room temperature. Then, the plate was washed three times with PBST and further incubated with $100 \mu \mathrm{L}$ 1:2,000 dilution of HRP-anti-M13 $\mathrm{mAb}$ (GE Healthcare) at room temperature for another hour. After another three washes with PBST, $100 \mu \mathrm{L}$ tetramethylbenzidine substrate solution was added and incubated in the dark for 15 minutes. The reaction was finally stopped by the addition of $50 \mu \mathrm{L} 1 \mathrm{M} \mathrm{H}_{2} \mathrm{SO}_{4}$ and absorbance at $450 \mathrm{~nm}$ measured with a microplate reader.

Monoclonal phage ELISA was carried out to determine individual colonies' ability to recognize dectin 1 specifically. In sum, 95 colonies were randomly picked from the third round of selection and inoculated in $200 \mu \mathrm{L} 2 \mathrm{xTY}$ medium (supplemented with $100 \mu \mathrm{g} / \mathrm{mL}$ ampicillin and $20 \mathrm{~g} / \mathrm{L}$ glucose) into separate wells of the cell-culture microplate. The plate was incubated overnight at $37^{\circ} \mathrm{C}$ with sharking at $200 \mathrm{rpm}$. A fresh $2 \mathrm{xTY}$ microplate containing $200 \mu \mathrm{L} 2 \mathrm{xTY}$ per well was inoculated with $2 \mu \mathrm{L}$ former plate cultures and incubated for 2 hour at $37^{\circ} \mathrm{C}$. After coinfection with helper phage $\left(10^{9}\right.$ per well), the latter plate was centrifuged at $1,000 \mathrm{rpm}$ for 10 minutes at room temperature and bacterial pellets resuspended in $200 \mu \mathrm{L} \mathrm{2xTY} \mathrm{(supplemented} \mathrm{with} 100 \mu \mathrm{g} / \mathrm{mL}$ ampicillin, $50 \mu \mathrm{g} / \mathrm{mL}$ kanamycin, and $1 \mathrm{~g} / \mathrm{L}$ glucose), and incubated overnight at $30^{\circ} \mathrm{C}$. The supernatant was detected by ELISA after 1,000 rpm centrifugation for 10 minutes on the next day.

Positive colonies were checked again with monoclonal phage ELISA. The positive phage with the highest absorbance was used to performed a colony PCR (forward primer 5'-ATA ATA AGG AAT TCC ATG GCT CGA GTG GAC CAA ACA CCG, reverse primer 5'-ATA ATC AAG CTT GCG GCC GCA TTC ACA GTC ACG ACA GTG CCA CCT C) 
using PCR Master Mix DNA polymerase (Tsingke Biotech). Finally, sequencing of the phage clone was determined by Tsingke Biotech.

\section{Expression, Purification, and Identification of Nanobodies Specific to Dectin I}

The gene of the nanobody was digested with BamHI (NEB) and NotI (NEB) and ligated with a similarly digested pET28 a vector by T4 DNA ligase (NEB). After verification by colony PCR (forward primer 5'-CGG GAT CCA TGG CTC GAG TGG ACC AAA CA, reverse primer 5'-ATA GTT TAG CGG CCG CAT TCA CAG TCA CGA CAG TGC) using the Master Mix DNA polymerase, the recombinant plasmid was transformed into competent E. coli Transetta-DE3 (Tsingke Biotech) cells by heat shock. Expression of the nanobody specific to dectin 1 was induced by $0.5 \mathrm{mmol} / \mathrm{L}$ isopropyl- $\beta$-D-thiogalactopyranoside (IPTG) in $16^{\circ} \mathrm{C}$ for 20 hours. Induction cells were collected and broken up by an ultrasonic cell crusher (JY88-II ultrasonic cell disruptor, Xinzhi Biological Technology), and the protein in the inclusion body was renatured by lysis buffer ( $8 \mathrm{M}$ urea, $50 \mathrm{mM}$ Tris-HCl, $300 \mathrm{mM} \mathrm{NaCl}, \mathrm{pH}$ ). Then, the recombinant nanobody was purified under gradient-washing using a nickel-ion column (GE Healthcare) and the elution product dialyzed in the solutions listed in Table 1. SDS-PAGE 12\% was used to analyze the expression and purification of the nanobody. The concentration of purified nanobodies was determined by the Bradford method. A typical indirect ELISA was carried out to determine the specificity of the nanobody to recombinant dectin 1 protein.

\section{Cell Culture and $A$. fumigatus Stimulation}

Human corneal epithelium cells (HCECs) were generously provided by the Ocular Surface Laboratory of Zhongshan Ophthalmic Center, Guangzhou, Guangdong, China. RAW 264.7 cells were purchased from the Chinese Academy of Sciences in Shanghai, China. The study on HCECs was approved by the Ethics Review Committee of the Affiliated Hospital of Qingdao University, Qingdao, Shandong, China (QYFYWZLL-26567). The standard A. fumigatus strain 3.0772 was purchased from the China General Microbiological Culture Collection Center in Beijing. HCECs were cultured in DMEM (Gibco) containing 10\% FBS (Gibco, San Diego, CA, USA) at $37^{\circ} \mathrm{C}$ in $5 \% \mathrm{CO}_{2}$. RAW 264.7 cells were cultured in high-glucose DMEM supplemented with $12 \% \mathrm{FBS}$ and incubated at $37^{\circ} \mathrm{C}$ in $5 \% \mathrm{CO}_{2}$. The inactive A. fumigatus hyphae (to a final concentration of $5 \times 10^{6} \mathrm{CFU} / \mathrm{mL}$ ) were prepared as per Xia et al and added to the cell culture for stimulation of dectin $1 .{ }^{23}$

\section{Immunofluorescence Staining of Cells}

HCECs or RAW $264.7(500 \mu \mathrm{L})$ cells at a concentration of $2 \times 10^{5} / \mathrm{mL}$ were seeded onto 24 -well plates with polyL-lysine-coated slips. When cultured to nearly $80 \%$ confluence, the cells were stimulated with $30 \mu \mathrm{L}$ A. fumigatus hyphae $\left(5 \times 10^{6} \mathrm{CFU} / \mathrm{mL}\right)$ for 16 hours. Then, cells were washed three times with PBST, coated with $4 \%$ paraformaldehyde (Solarbio) for 10 minutes, and blocked with 1:10 diluted goat serum (Solarbio) for 30 minutes at room temperature after another three washes with PBST. Purified recombinant nanobodies $(100 \mu \mathrm{L}, 1 \mathrm{mg} / \mathrm{mL})$ were added and incubated with cells at $4{ }^{\circ} \mathrm{C}$ overnight. PBS or aspecific nanobodies of equal volume were used as blank and negative controls, respectively. Subsequently, the HCECs were incubated with $100 \mu \mathrm{L}$ 1:1,000 mouse antishark VNAR antibodies and 100 $\mu \mathrm{L}$ 1:1,000 FITC-conjugated goat antimouse IgG antibodies (Abcam) at $37^{\circ} \mathrm{C}$ for 1 hour successively. The RAW 264.7 cells were incubated with $100 \mu \mathrm{L}$ 1:1,000 rabbit anti-His tag antibodies and $100 \mu \mathrm{L}$ 1:1,000 FITC-conjugated goat antirabbit IgG antibodies (Abcam) at $37^{\circ} \mathrm{C}$ for 1 hour successively. Then, PBST was used to wash the cells three times. Cell nuclei were stained with $100 \mu \mathrm{L}$ 1:100 DAPI for 10 minutes and washed three times with PBST. Fluorescent signals were finally detected with a Zeiss Axiovert microscope at 200× magnification.

Table I Components of dialysate solution

\begin{tabular}{|l|l|}
\hline & Ingredients \\
\hline Buffer I & $50 \mathrm{mM}$ Tris, $150 \mathrm{mM}$ NACl, $2 \mathrm{mM}$ EDTA, $4 \mathrm{mM}$ GSH, 0.4 mM GSSG, 0.4 M L-arginine, 10\% glycerin (pH 8) \\
Buffer 2 & $50 \mathrm{mM}$ Tris, $150 \mathrm{mM} \mathrm{NACl,} \mathrm{10 \%} \mathrm{glycerin} \mathrm{(pH} \mathrm{8)}$ \\
\hline
\end{tabular}


Table 2 Nucleotide sequences of human primers for rT-PCR

\begin{tabular}{|c|c|c|}
\hline Gene & GenBank identifier & Primer sequence (5'-3') \\
\hline h $\beta$-GAPDH & NM_00II0I.5 & $\begin{array}{l}\text { F: TGG CAC CCA GCA CAA TGA A } \\
\text { R: CTA AGT CAT AGT CCG CCT AGA AGC A }\end{array}$ \\
\hline hILI $\beta$ & NM_000576.2 & $\begin{array}{l}\text { F: GCT GAT GGC CCT AAA CAG ATG AA } \\
\text { R: TCC ATG GCC ACA ACA ACT GAC }\end{array}$ \\
\hline hlL6 & NM_000600.4 & $\begin{array}{l}\text { F: AAG CCA GAG CTG TGC AGA TGA GTA } \\
\text { R: TGT CCT GCA GCC ACT GGT TC }\end{array}$ \\
\hline$M \beta$-actin & NM_007393.5 & $\begin{array}{l}\text { F: GAT TAC TGC TCT GGC TCC TAG C } \\
\text { R: GAC TCA TCG TAC TCC TGC TTG C }\end{array}$ \\
\hline MILI $\beta$ & NM_00836I.4 & $\begin{array}{l}\text { F: CGC AGC AGC ACA TCA ACA AGA GC } \\
\text { R: TGT CCT CAT CCT GGA AGG TCC ACG }\end{array}$ \\
\hline MIL6 & NM_00 I 3 |4054.I & $\begin{array}{l}\text { F: TGA TGG ATG CTA CCA AAC TGG A } \\
\text { R: TGT GAC TCC AGC TTA TCT CTT GG }\end{array}$ \\
\hline
\end{tabular}

\section{Anti-inflammatory Effect of Nanobodies in HCEC Model}

HCECs $(1.5 \mathrm{~mL})$ at a concentration of $3 \times 10^{5} / \mathrm{mL}$ were seeded into 12 -well plates and cultured until $70 \%-80 \%$ confluence, then pretreated with $100 \mu \mathrm{L}(1 \mathrm{mg} / \mathrm{mL})$ of nanobodies specific to dectin 1 dissolved in PBS (Solarbio) for 2 hours. After stimulation with inactive A. fumigatus hyphae $\left(5 \times 10^{6} \mathrm{CFU} / \mathrm{mL}\right)$ for 8 or 16 hours, the cells and supernatant were collected for RT-PCR and ELISA tests, respectively. Protein levels of IL1 $\beta$ and IL6 (n=6/group/ time) were assessed using human ELISA kits (ELISA Max Deluxe, BioLegend) according to the protocols. Absorbance at $450 \mathrm{~nm}$ was detected with a reference wavelength of $570 \mathrm{~nm}$ (VersaMax plate reader, Molecular Devices). mRNA levels of IL1 $\beta$ and IL6 were assessed by RT-PCR ( $n=6 /$ group/time). Total RNA of the cells was extracted using a n RNAextraction reagent (RNAiso Plus, Solarbio) and quantified by NanoDrop (Thermo Fisher Scientific). mRNA expression of $\beta$-actin, one of the housekeeping genes, was used as a reference. HiScript III RT SuperMix for qPCR (Vazyme) was used to reverse RNA into complementary cDNA. Quantitative RT-PCR (primers shown in Table 2) was performed using ChamQ SYBR Color qPCR Master Mix (Vazyme). Values were recorded to the verify the fold-change ratios of proinflammatory cytokines. Cells pretreated with PBS and nonspecific nanobodies were used as blank and negative controls, respectively.

\section{Specificity and Anti-inflammatory Effect of Nanobodies in Mouse Model}

C57BL/6 mice (female, 8 weeks old) were purchased from Pengyue Laboratory Animal (Jinan, China) and treated in accordance with the ARVO statement for the Use of Animals in Ophthalmic and Visual Research. All experimental protocols were performed in accordance with the National Institution of Health's Guidelines for the Care and Use of Laboratory Animals and every effort was made to minimize both the number of animals and their suffering. The study was approved by the Ethics Review Committee of the Affiliated Hospital of Qingdao University, Qingdao, Shandong, China (QYFYWZLL-26567). All corneas were separately inspected under slit-lamp microscopy before experimental use. After anesthetisia by intraperitoneal injection with $8 \%$ chloral hydrate, central corneal epithelia of mouse eyes were removed within $2 \mathrm{~mm}$ diameter. A $10 \mu \mathrm{L}$ aliquot containing $10^{8} \mathrm{CFU} / \mathrm{mL}$ of A. fumigatus was coated on the ocular surface and a soft contact lens placed. Subsequently, the eyelids of the mice were sutured. Then, the eye of each mouse was injected with $5 \mu \mathrm{L}$ specific nanobodies (to a final concentration of $5 \mathrm{mg} / \mathrm{mL}$ ) or sterile PBS subconjunctivally at 1 day postinfection and with $5 \mu \mathrm{L}$ specific nanobodies (to a final concentration of $5 \mathrm{mg} / \mathrm{mL}$ ) or PBS three times daily from day 2 postinfection. Epithelia of the control corneas were removed without A. fumigatus stimulation. No treatment was administered to normal corneas.

Mouse eyeballs ( $\mathrm{n}=3 /$ group/time) were embedded and frozen. The corneas of the normal group and A. fumigatusinfected mice were sectioned to $10 \mu \mathrm{m}$. Corneal lesions $(10 \mu \mathrm{m})$ were acquired and then fixed in acetone. After being blocked with goat serum (1:100), sections were incubated with $30 \mu \mathrm{L}$ nanobodies, followed by $30 \mu \mathrm{L}$ monoclonal rabbit anti-His-tag antibodies and FITC-conjugated goat antirabbit $\mathrm{IgG}$ antibodies $\left(1: 1,000\right.$, Abcam) at $37^{\circ} \mathrm{C}$ for 1 hour 
successively. Cell nuclei were stained with DAPI. Images were photographed with a fluorescence microscope (Zeiss Axio Vert, 200×).

There were six mice in each group ( $\mathrm{n}=6 /$ time/group). Based on the observation under a slit lamp at 1,3 , and 5 days postinfection, the severity of keratitis was evaluated by a clinical score that was the sum of the three aspects of cornea opacity density, opacity area, and surface regularity - each of which had a grade of 0 to 4 . Severity was classed as normal (0), mild (1-5), moderate (6-9), and severe (10-12). ${ }^{24}$ Taking a normal cornea as an example, a live cornea would be given a score of 0 for each class, thus yielding a total score of 0 . Mouse corneas removed with a scalpel and microscissor at the indicated times after treatment were prepared for RT-PCR and ELISA, respectively.

\section{Cytotoxicity Assessment of Nanobodies}

HCECs $\left(100 \mu \mathrm{L}, 3 \times 10^{4} / \mathrm{mL}\right)$ were suspended and seeded into a 96 -well plate and cultured at $37^{\circ} \mathrm{C}$ for 24 hours. Nanobodies specific to dectin 1 diluted in PBS for various concentrations were added to each well. After incubation for another 24 hours, $10 \mu \mathrm{L}$ CCK8 solution (MCE) was added to each well. The plates were incubated for 2 hours and absorbance was measured by a microplate reader (Solarbio) at $450 \mathrm{~nm}$. Each sample had six replicates.

\section{Statistical Analysis}

Differences in clinical scores between two groups at each time point were analyzed by Mann-Whitney $U$ test. Statistical significance between two groups was evaluated by two-tailed Student's $t$-test, and one-way ANOVA was used to make comparisons among three or more groups. Multiple comparisons among groups were performed using Bonferroni's test. GraphPad Prism 7.0 and SPSS 23.0 were used for statistical analyses, with values presented as means \pm SD. $P<0.05$ was considered statistically significant. All experiments were repeated at least three times.

\section{Results}

\section{Screening of Nanobody Gene Specific to Dectin I}

Phages displaying nanobodies specific to dectin 1 were panned for three rounds using immunotubes coated with different concentrations of recombinant dectin 1 protein. Polyclonal phage ELISA results showed that the phages specific to dectin 1 were enriched as panning progressed. After the first round of panning, the value of $\mathrm{OD}_{450}$ values showed no obvious difference from the negative-control group, but a significant increase in binding ability was observed from the first to the third rounds (Figure 1A). A total of 95 phages were randomly picked from the third round panning and then analyzed by monoclonal phage ELISA, and 26 showed high absorbance (at least three times that of control wells, Figure 1C). ${ }^{25}$ Four phages with the highest absorbance were selected to repeat the phage ELISA in order to avoid false-positive reactivity. The absorbance of these was at least three times that of the negative control (Figure 1B). The phage with the strongest antigen-specific binding capacity was selected for colony PCR to amplify the nanobody gene. A gene band about $500 \mathrm{bp}$ appeared in the agarose gel (Figure 2).

\section{Expression and Purification of Nanobodies}

Sequencing results showed that nanobodies were shark-derived with a complete CDR3 (Figure 3A). Therefore, this gene was used as the gene sequence for specific nanobody expression. The gene of nanobody specific to dectin 1 was recombined with the plasmid after restriction by T4 DNA ligase to construct a new protein-expression vector. A solid plate with kanamycin was used to select a positive expression vector (Figure 3B). PCR and nucleic acid electrophoresis were used to verify the construction of plasmid-expression vectors. Nucleic acid electrophoresis in a $1 \%$ agarose gel showed a bright band around $350 \mathrm{bp}$ (Figure 3C).

The expression vector was transformed into competent E. coli Transetta-DE3 by heat shock. Expression of the recombinant nanobodies was induced by $0.5 \mathrm{mmol} / \mathrm{L}$ IPTG at $16^{\circ} \mathrm{C}$ overnight. After induction with $0.5 \mathrm{mmol} / \mathrm{L} \mathrm{IPTG}$, the $17 \mathrm{kDa}$ protein band was present in the precipitation of E. coli and broken up by the ultrasonic cell crusher, as shown on $12 \%$ SDS-PAGE stained with Coomassie (Figure 4A). Nanobodies were purified by the nickel-ion column under different concentrations of imidazole. When passing through the column, the His-tag carried by the nanobodies 
A

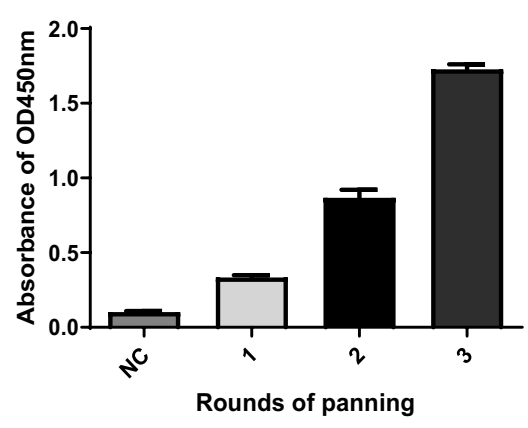

C

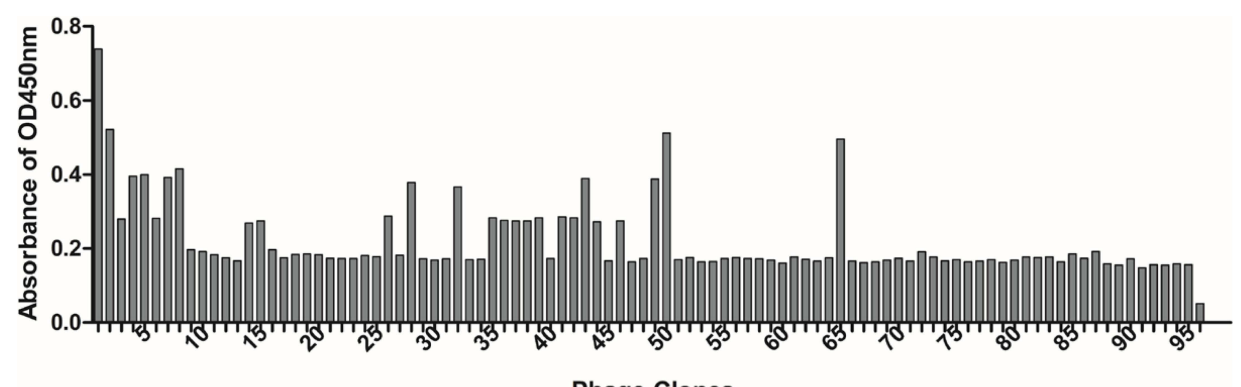

B

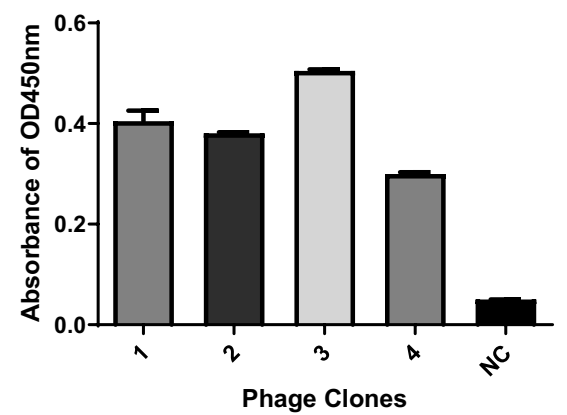

Figure I Screening of special nanobody gene against dectin I. (A) Polyclonal phage ELISA results. The phages generated from the original library were used as negative controls, and affinity of the panned phages showed a significant increase from the first round to the third round of panning. (B) Monoclonal phage ELISA results of four phages. NC, negative control. (C) Monoclonal phage ELISA results. I-95, clones selected from the third round of panning; 96, negative control.

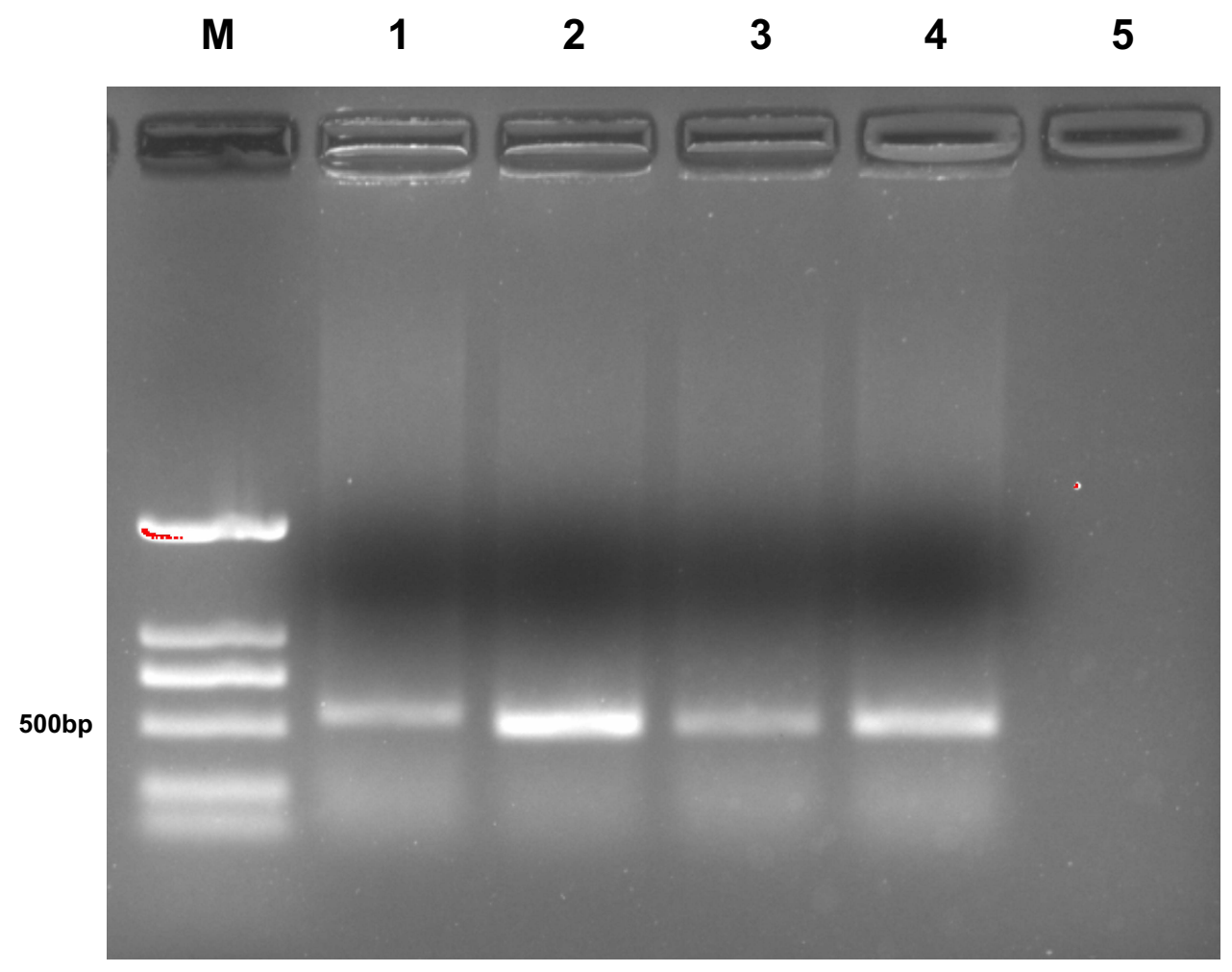

Figure 2 Agarose-gel electrophoresis of the positive clones. M, DNA marker DL2000; lanes I-4, positive clones; lane 5, negative control. 
A

SMARVDQTPQTITKETGESLTINCVLRDSNCALSSTYWYRKKSGSTNEES ISKGGRCVETVNSGSKSFSLRINDL
\begin{tabular}{|l|r|r|r|r|r|r|r|}
\hline 10 & 20 & 30 & 40 & 50 & 70
\end{tabular}

\section{TVEDSGTYRCNVGDQAGYDPLPGGLRLWRGVYGGGTVVTVNAA}

$80|+90| \quad 100|+110|+\mid 119$

\section{CDR 3}

B

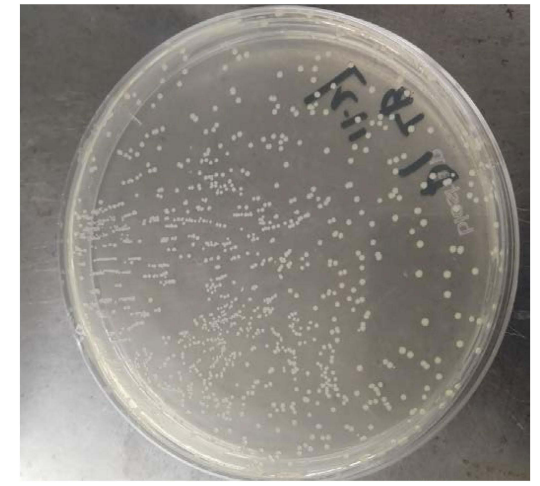

C

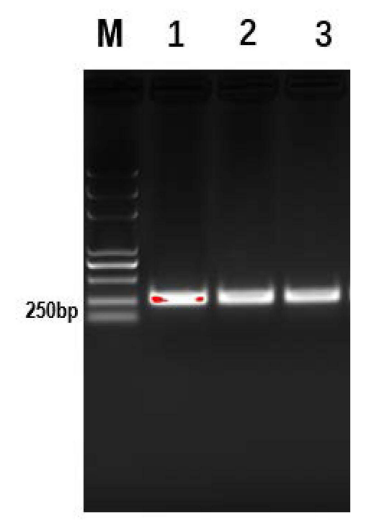

Figure 3 Construction of expression vector of dectin I-specific nanobodies. (A) The 119 amino-acid sequence of the nanobody. The area marked in red is the CDR3. (B) Nucleic acid electrophoresis of the target gene (M, DNA marker DL2000). Lanes I-3, target gene. (C) Screening of positive clones on solid plates with kanamycin.

\section{A}

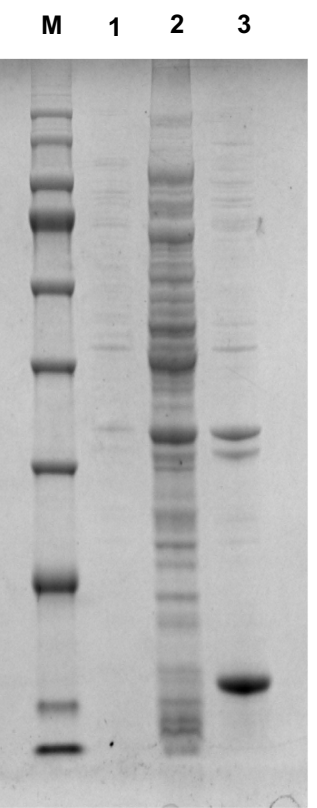

B

M

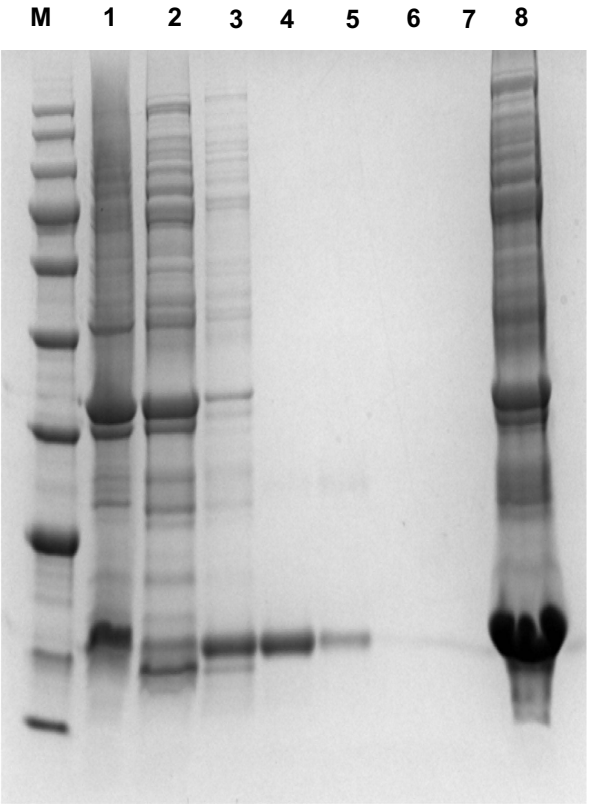

C
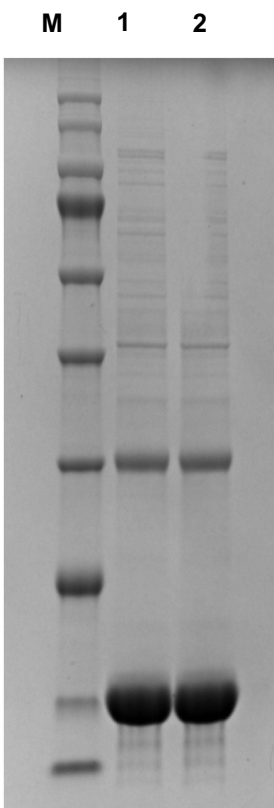

Figure 4 Expression and purification of soluble nanobodies. (A) M, protein marker; I:, bacterium protein before induction; 2 , $16^{\circ} \mathrm{C}$ supernatant; 3 , $16^{\circ} \mathrm{C}$ precipitation. $($ B) M, Protein marker; I, upper sample; 2, effluent; 3-7, 20, 50, 100 mM, 200 mM, 500 mM imidazole-elution component; 8: $16^{\circ} \mathrm{C}$ precipitation. (C) M:, protein marker; I-5:, protein after dialysis. 
interacted with nickel ions. Imidazole of low concentration was used to wash away impurities, and imidazole of high concentration eluted the target protein (Figure 4B). In order to remove imidazole and other impurities components left, the eluted outflow solution was dialyzed to obtain the final purified nanobodies. SDS-PAGE $12 \%$ was used to analyze the purification of the nanobodies (Figure 4C). Bright protein bands appeared around $17 \mathrm{kDa}$. The total protein content of nanobody was determined by the Bradford method. After measurement, the yield of nanobodie specific to dectin 1 was $5 \mathrm{mg} / \mathrm{L}$.

\section{Affinity Determination of Nanobodies Specific to Dectin I}

The specificity of nanobodies for binding to dectin 1 were determined by ELISA. Dectin 1 nanobodies at final concentrations of 5, 2.5, 1 , and $0.5 \mathrm{mg} / \mathrm{mL}$ were added to recombinant dectin 1-coated microplates. According to the results, $\mathrm{OD}_{450}$ of nanobodies specific to dectin 1 at a concentration of $5 \mathrm{mg} / \mathrm{mL}$ was about $3 . \mathrm{OD}_{450}$ decreased with decreased nanobody concentration. $\mathrm{OD}_{450}$ of $2.5 \mathrm{mg} / \mathrm{mL}$ is slightly lower than that of $5 \mathrm{mg} / \mathrm{mL}$. $\mathrm{OD}_{450}$ of $1 \mathrm{mg} / \mathrm{mL}$ decreased significantly, and for $0.5 \mathrm{mg} / \mathrm{mL}$ was still three times that of the negative control. $\mathrm{OD}_{450}$ of negative nanobodies was not significantly different from that of blank controls (Figure 5). To further verify the ability of nanobodies to bind to dectin 1 expressed in cells, we selected HCECs and RAW 264.7 cells for immunofluorescence staining. Compared with the blank control group and negative-nanobody group, stronger fluorescence was seen in the membrane and cytoplasm of nanobodies specific to dectin 1. Furthermore, fluorescence was stronger still in cells stimulated by A. fumigatus hyphae (Figure 6A and B).

\section{Anti-inflammatory Effects of Nanobodies Specific to Dectin I in A. fumigatus Keratitis} In order to determine whether nanobodies specific to dectin 1 could inhibit the expression of proinflammatory cytokines, RT-PCR and ELISA were used to detect the expression of IL1 $\beta$ and IL6. Pretreatment with nanobodies 2 hours prior to A. fumigatus stimulation markedly downregulated mRNA and protein levels of IL1 $\beta$ and IL6 in HCECs (Figure 7A-D). The differences were statistically significant $(P<0.001)$. A mouse model of A. fumigatus keratitis was established and

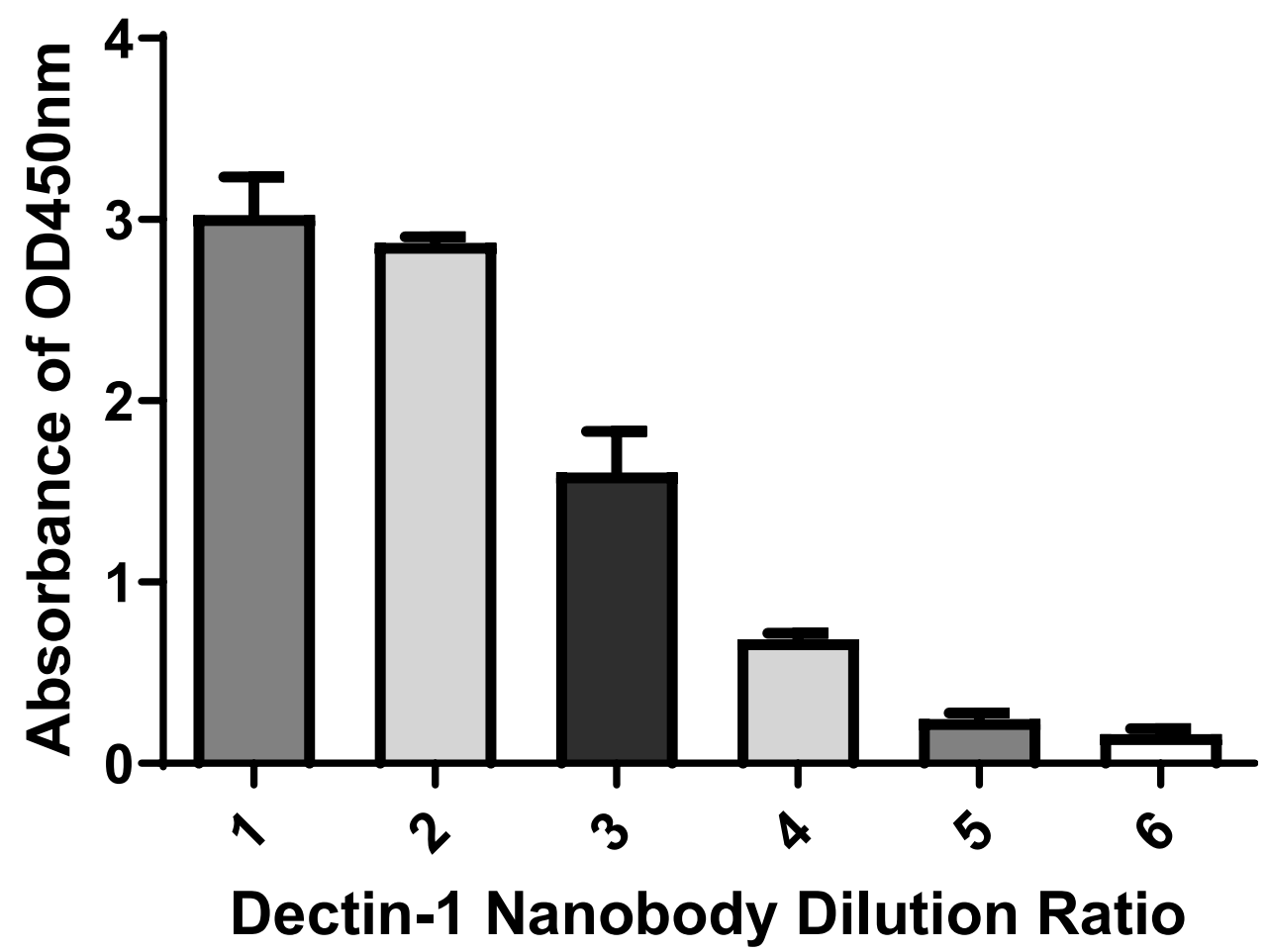

Figure 5 Specificity determination of nanobody specific to dectin I. Binding activity and specificity of the were analyzed by indirect ELISA. I-4: $5,2.5$, I, and $0.5 \mathrm{mg} / \mathrm{mL}$ of nanobody. 5, other negative used as negative control; 6, PBS used as blank control. 
A

DAPI
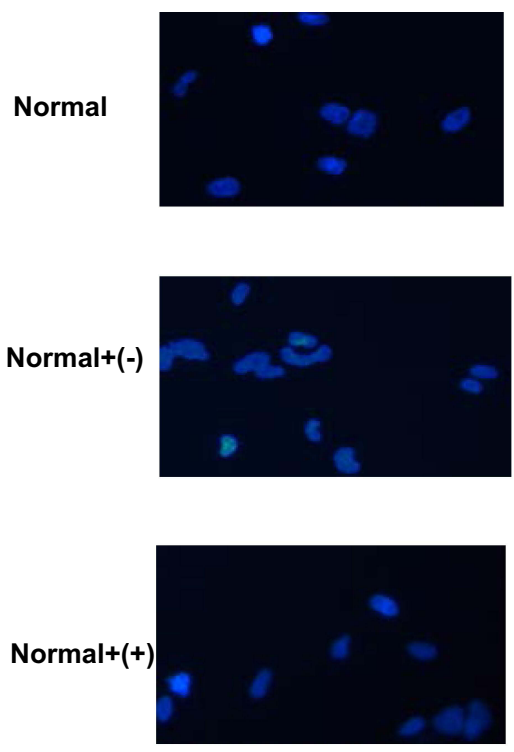

$\mathrm{AF}+(-)$
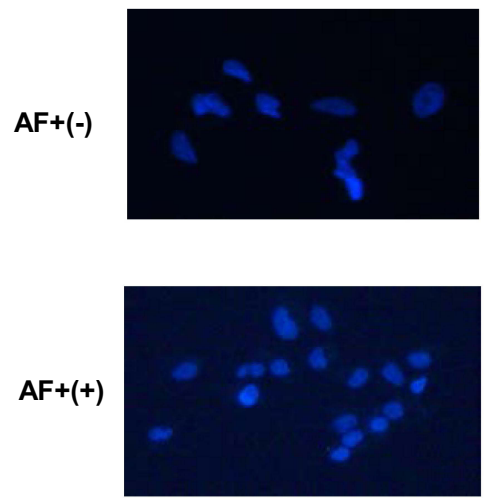

B

DAPI
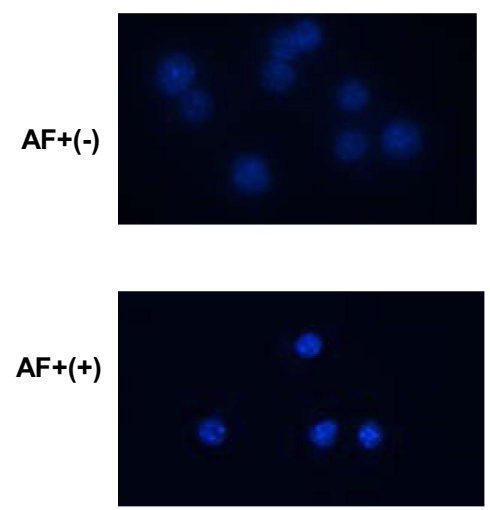

FITC
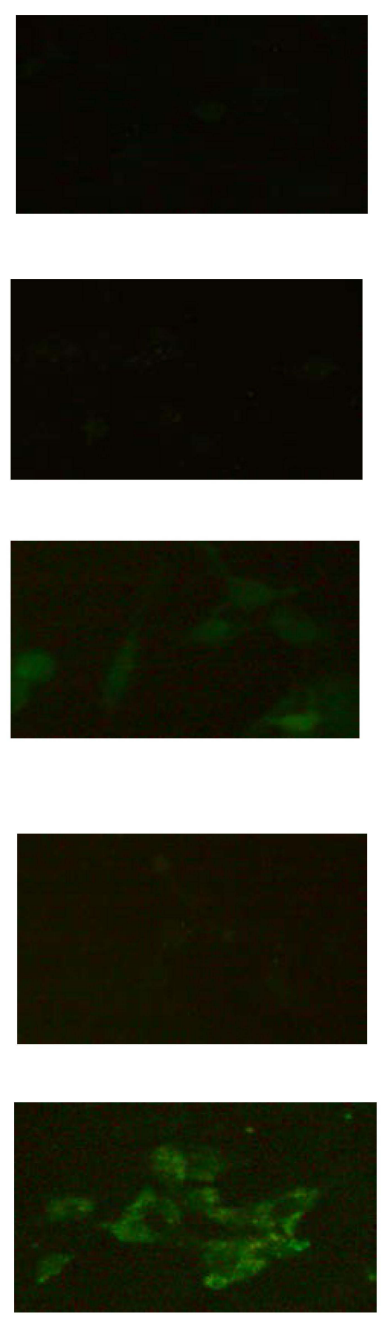

FITC
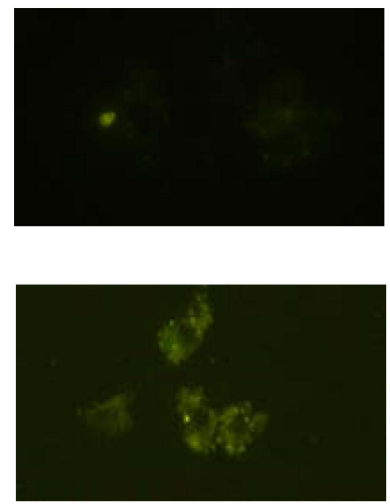

Merge
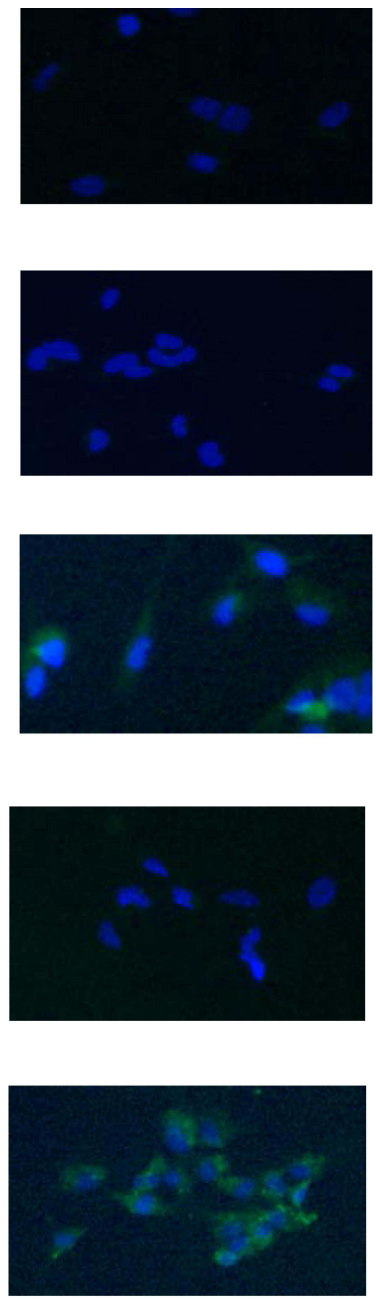

Merge
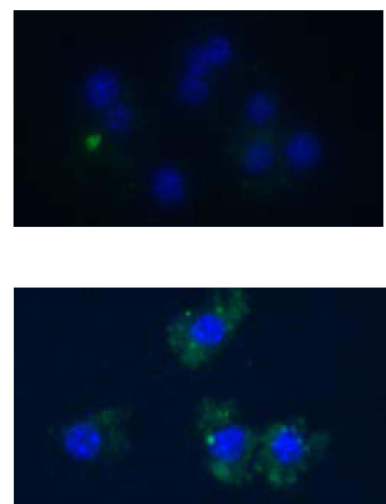

Figure 6 Immunofluorescence analysis of binding activity of nanobody specificies. (A) HCECs with or without A. fumigatus stimulation were incubated with nanobodies and detected with FITC-streptavidin (green fluorescence). Negative nanobodies and PBS were used as negative controls. DAPI was used for nuclear staining (blue fluorescence). (B) RAW 264.7 cells stimulated by A. fumigatus were incubated with nanobodies. Negative nanobodies were used as negative controls. 

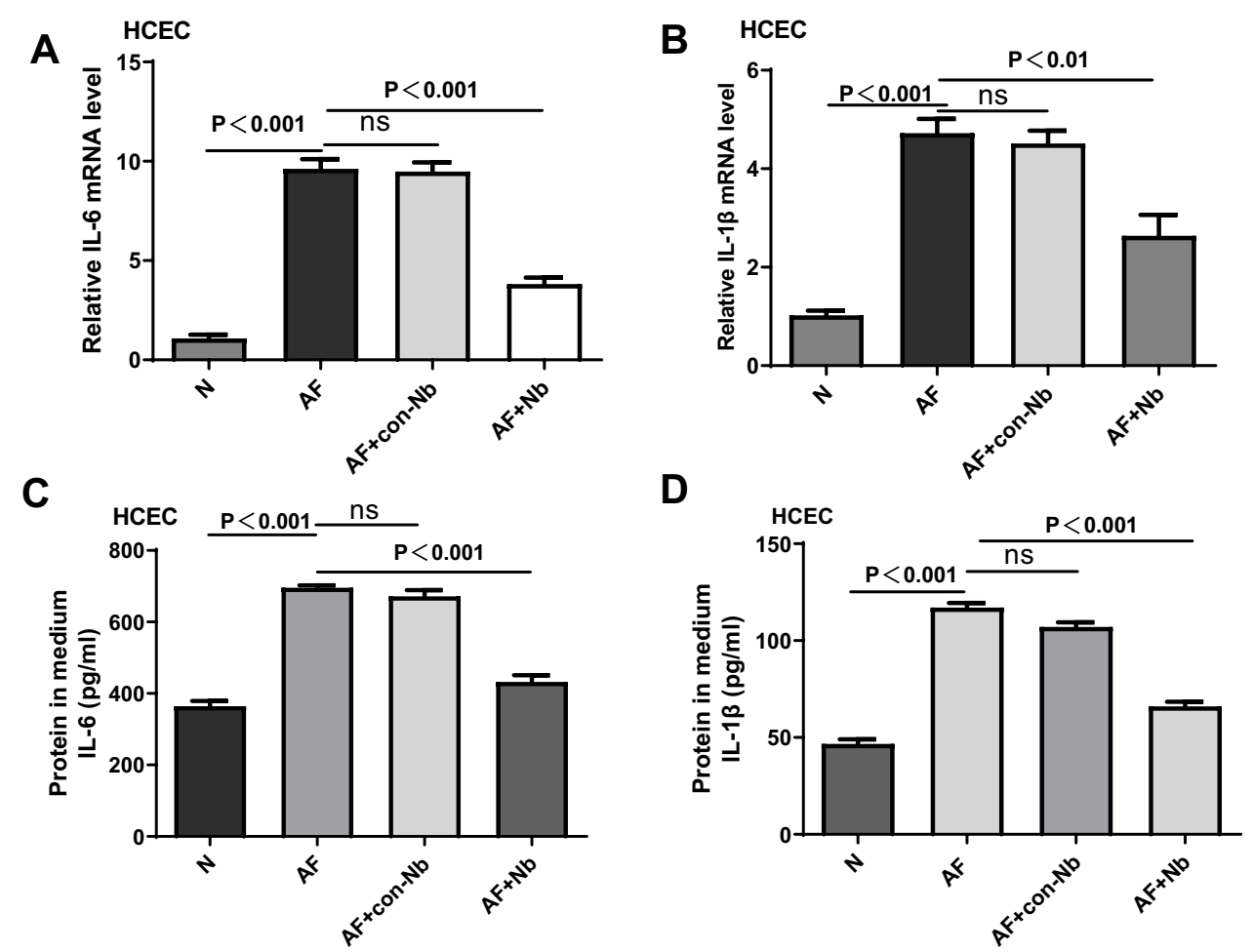

Figure 7 Nanobody treatment inhibited the production of cytokines in HCECs stimulated by A. fumigatus. Compared with PBS treatment, nanobody treatment markedly decreased mRNA expression of IL6 (A) and ILI $\beta$ (B). ELISA analysis showed that nanobody treatment reduced the protein expression of IL6 (C) and ILI $\beta$ (D) compared with PBS treatment. Data presented as means \pm SD of three independent experiments. $p P<0.05$ considered statistically significant.

clinical scores used to evaluate the degree of inflammation. As shown in Figure 8A and B, the nanobodies alleviated the inflammatory response and reduced clinical scores. Immunofluorescence staining showed that the fluorescence in the corneas of the normal group was weak, but stronger in the corneal epithelium 3 days after infection (Figure 8C). The nanobodies decreased cytokine levels in infected corneas. (Figure $8 \mathrm{D}-\mathrm{G}$ ). This difference was statistically significant $(P<0.05)$.

\section{Effects of Nanobodies on Proliferation of HCECs}

CCK8 analysis was used to evaluate the effect of nanobodies on the proliferation of HCECs. HCECs were seeded onto 96-well cell-culture plates and treated with different concentrations of nanobodies specific to dectin 1 for 24 hours. The nanobodies did not affect the viability of HCECs (Figure 9).

\section{Discussion}

Fungal keratitis is a serious corneal disease that can cause visual impairment. ${ }^{26-28}$ It is caused by infection by pathogenic fungi and usually elicits ulceration or even perforation of the infected cornea. ${ }^{29-31}$ The lack of high-efficiency, lowtoxicity, and high-permeability drugs for corneal fungal infections means poor prognosis. ${ }^{32-34}$ Nanobodies that naturally lack light chains are unique antibodies first found in the sera of sharks and camelids. ${ }^{35}$ Because they possess many desirable attributes, such as small molecules, low immunogenicity, strong penetration, and high binding affinity, different types nanobodies have become novel diagnosis and treatment methods for tumors and infectious diseases. ${ }^{36-38}$ We constructed a nanobody specific to dectin 1, which is an important PRR in fungal infection. We also verified that this nanobody can bind to the dectin 1 antigen and relieve the inflammatory response in fungal keratitis. ${ }^{39,40}$

As stated in other studies, panning of a nanobody-gene library with phage display is a practical method of preparing antibodies. Phage display is a feasible method for selection of a particular domain of an antigen. ${ }^{41,42}$ Through the construction of a large-capacity natural nanobody-gene library, a variety of nanobodies can be prepared without 
A

1D

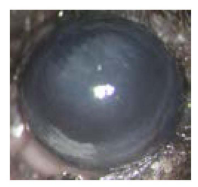

Dectin-1Nb
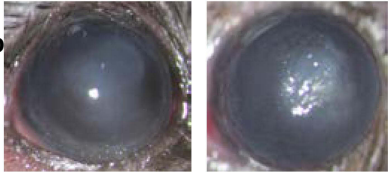

C

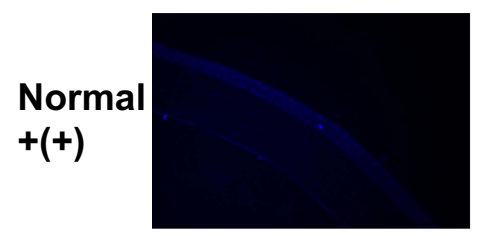

5D
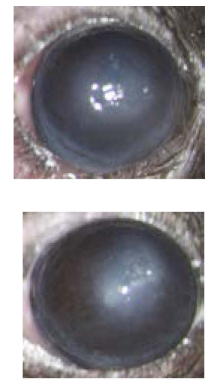

B

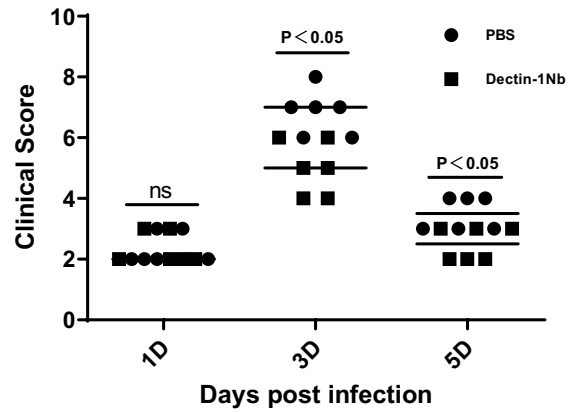

FITC
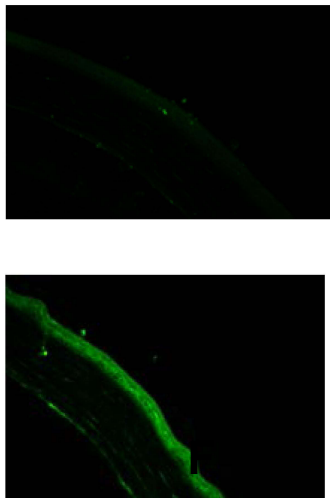

Merge
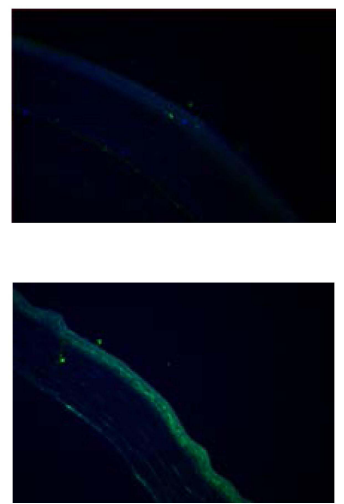

D

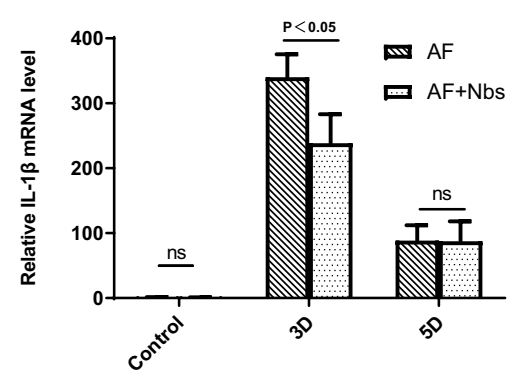

F

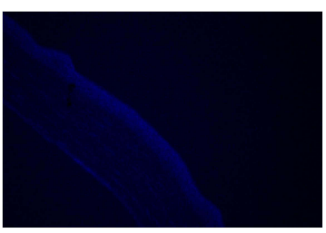

E

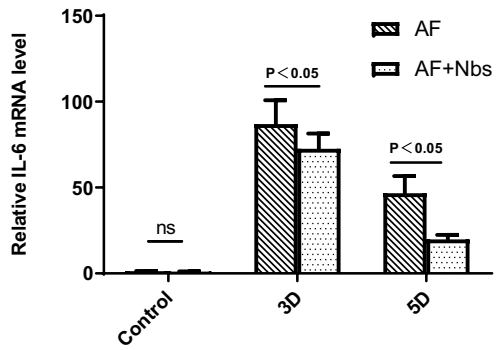

G

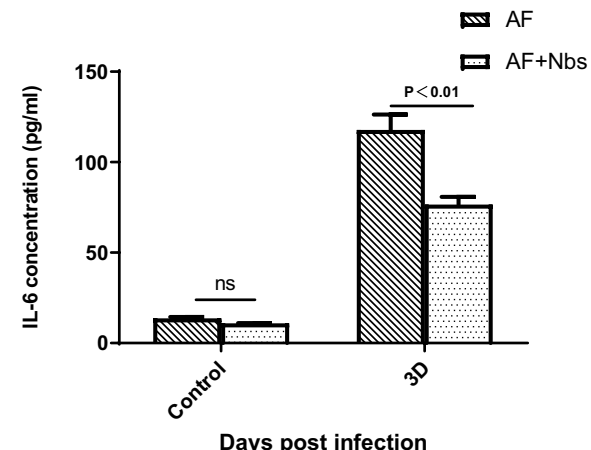

Figure 8 Anti-inflammatory effect of nanobody specific to dectin I in mouse A. fumigatus keratitis. (A) Photographs of nanobody- and PBS-treated corneas taken with a slit lamp at 3 and 5 days postinfection. Nanobody treatment relieved the severity of fungal keratitis in mice. Magnification $25 \times$. (B) Significant reductions in clinical scores were observed at 3 and 5 days in nanobody-treated corneas $(n=6)$ compared with PBS-treated corneas $(n=6)$. (C) Immunofluorescence images taken under fluorescence microscopy. The fluorescence in the cornea of the normal group was weak, and the fluorescence in the corneal epithelium was stronger 3 days after infection. Blue, nuclear staining (DAPI); green, dectin I staining. Magnification 200x. (D-G) ILI $\beta$ and IL6 expression in PBS- and nanobody-treatment groups. 


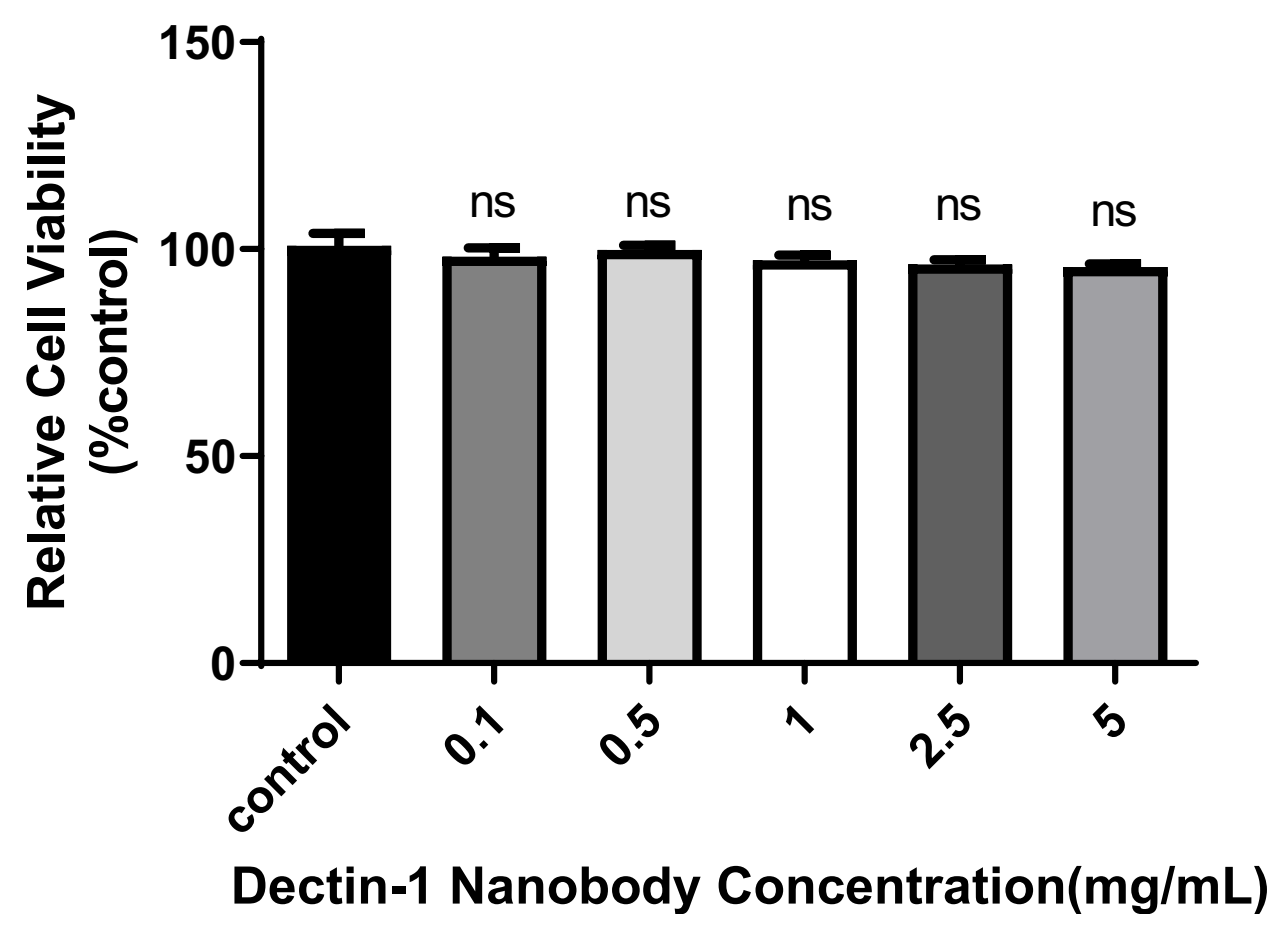

Figure 9 Effects of nanobodies on the proliferation of HCECs. HCECs were seeded onto 96 -well cell-culture plates and treated with different concentrations of specific nanobodies of dectin I for 24 hours. $p P<0.05$ considered statistically significant.

Abbreviation: ns, not significant.

immunization. For instance, nanobodies specific to LPS can be panned out through natural gene libraries derived from Camelid. ${ }^{42}$ In our study, after three rounds' selection, the gene sequence of a nanobody specific to dectin 1 was selected. The gene was expressed in the inclusion body of $E$. coli with a high yield. The $12 \%$ SDS-PAGE result showed it was specific to dectin 1 at $17 \mathrm{kDa}$. This consistent with results of previous studies showing nanobody molecular weight of about $15 \mathrm{kDa}$. The specificity of our nanobody was further assessed by indirect ELISA and immunofluorescence staining. Indirect ELISA results suggested that it had strong binding ability to dectin 1 protein. Due to their small dimensions and permeability, nanobodies have been widely used as probes for immunoimaging and diagnostic assays. ${ }^{43}$ For instance, in one study PEDV-infected Vero cells were immunofluorescence-stained with S7 nanobodies. Compared with control Vero cells, those infected with PEDV were well stained by the S7 nanobody. ${ }^{14}$ Our immunofluorescence results showed expression of dectin 1 on HCECs and RAW 264.7 cells. These nanobodies can combine with the dectin 1 expressed in the mouse cornea. This further illustrated that dectin 1 antigens and nanobodies can interact with high affinity. These results provided a foundation for our research on anti-inflammatory effect of nanobodies in HCECs and a mouse model.

Extensive research has demonstrated that nanobodies play a significant role in several inflammatory diseases. ${ }^{44-46}$ In related experiments, nanobodies specific to TLR4 treatment significantly decreased mRNA and protein levels of proinflammatory cytokines in NR8383 cells. ${ }^{47}$ Consistently with that research, our in vitro tests showed that compared with negative nanobody treatment, specific nanobody treatment significantly suppressed mRNA and protein expression of IL1 $\beta$ and IL6 in HCECs stimulated by A. fumigatus. Nanobody specifically inhibits P2X7 on immune cells was designed to play a anti-inflammatory reaction which is the first nanobody that blocks the channel protein. In one study, systematic injection of nanobodies into mice blocked P2X7 on $\mathrm{T}$ cells and macrophages in vivo and ameliorated experimental glomerulonephritis and allergic contact dermatitis. ${ }^{20}$ Research has shown that orally administered Lactococcus lactis secreting an anti-TNF nanobody had anti-inflammatory efficacy in chronic colitis. ${ }^{19}$ Injecting nanobodies against TLR4 into mice can successfully reduce excessive inflammatory reactions in sepsis without obvious side effects. ${ }^{47}$ We found that specific nanobody treatment alleviated inflammation and improved the outcome of fungal keratitis. Clinical scores and photographs taken with a slit lamp showed less corneal opacity in nanobody-treated corneas than PBS-treated ones, and nanobody treatment reduced the expression of inflammatory factors in fungal keratitis in 
mice. These results show that this nanobody can restrain excessive inflammation induced by A. fumigatus in HCECs and corneas. hese nanobodies can have great clinical application potential in the treatment of A. fumigatus infection by alleviating excessive inflammatory responses. In addition, cytotoxicity assessment in HCECs was performed to verify the low toxicity of the nanobodies.

\section{Conclusion}

Nanobodies specific to dectin 1 were successfully expressed through a microbial system with a high yield, interacted with dectin 1 antigen with high affinity, and had an anti-inflammatory effect in a mouse fungal keratitis model. All the results implied that these nanobodies could be used as potential therapeutic agent for the treatment of fungal keratitis.

\section{Ethics}

Our experiments were carried out in accordance with the Basel Declaration and the ethical guidelines of the International Council for Laboratory Animal Science with the approval of an experimental animal ethics committee (QYFYWZLL26567).

\section{Acknowledgments}

This work was supported by the National Natural Science Foundation of China (81870632), Natural Science Foundation of Shandong Province (ZR2017BH025), Shandong Province Key Research and Development Plan (2019GSF107022), Taishan Scholar Project of Shandong Province (tsqn201812151), and Youth National Natural Science Foundation of China (81500695).

\section{Disclosure}

Xing Liu and Jianxin Sui are joint first authors. The authors declare no conflict of interest.

\section{References}

1. Hu LT, Du ZD, Zhao GQ, et al. Role of TREM-1 in response to aspergillus fumigatus infection in corneal epithelial cells. Int Immunopharmacol. 2014;23(1):288-293. doi:10.1016/j.intimp.2014.09.011

2. Fan Y, Li C, Peng X, et al. Perillaldehyde ameliorates aspergillus fumigatus keratitis by activating the Nrf2/HO-1 signaling pathway and inhibiting dectin-1-mediated inflammation. Invest Ophthalmol Vis Sci. 2020;61(6):51. doi:10.1167/iovs.61.6.51

3. Nielsen SE, Nielsen E, Julian HO, et al. Incidence and clinical characteristics of fungal keratitis in a Danish population from 2000 to 2013 . Acta Ophthalmol. 2015;93(1):54-58. doi:10.1111/aos.12440

4. Garg P, Roy A, Roy S. Update on fungal keratitis. Curr Opin Ophthalmol. 2016;27(4):333-339. doi:10.1097/ICU.0000000000000272

5. Niu Y, Zhao G, Li C, et al. Aspergillus fumigatus increased PAR-2 expression and elevated proinflammatory cytokines expression through the pathway of PAR-2/ERK1/2 in cornea. Invest Ophthalmol Vis Sci. 2018;59:166-175.

6. Xie L, Zhong W, Shi W, et al. Spectrum of fungal keratitis in north China. Ophthalmology. 2006;113(11):1943-1948. doi:10.1016/j. ophtha.2006.05.035

7. van de Veerdonk FL, Gresnigt MS, Romani L, Netea MG, Latge JP. Aspergillus fumigatus morphology and dynamic host interactions. Nat Rev Microbiol. 2017;15:661-674. doi:10.1038/nrmicro.2017.90

8. Yuan K, Zhao G, Che C, et al. Dectin-1 is essential for IL-1 $\beta$ production through JNK activation and apoptosis in Aspergillus fumigatus keratitis. Int Immunopharmacol. 2017;52:168-175. doi:10.1016/j.intimp.2017.09.008

9. Slowik M, Biernat M, Urbaniak-Kujda D, et al. Mycotic infections of the eye. Adv Clin Exp Med. 2015;24(6):1113-1117. doi:10.17219/acem/ 50572

10. FlorCruz NV, Evans JR. Medical interventions for fungal keratitis. Cochrane Database Syst Rev. 2015;4:Cd004241.

11. Bajracharya L, Gurung R. Outcome of therapeutic penetrating keratoplasty in a tertiary eye care center in Nepal. Clin Ophthalmol. 2015;9:2299-2304. doi:10.2147/OPTH.S92176

12. Lee JE, Sun Y, Gjorstrup P, et al. Inhibition of corneal inflammation by the resolvin e1. Invest Ophthalmol Vis Sci. 2015;56(4):2728-2736. doi:10.1167/iovs.14-15982

13. Ebrahimizadeh W, Mousavi Gargari S, Rajabibazl M, Safaee Ardekani L, Zare H, Bakherad H. Isolation and characterization of protective anti-LPS nanobody against V. cholerae O1 recognizing Inaba and Ogawa serotypes. Appl Microbiol Biotechnol. 2013;97(10):4457-4466. doi:10.1007/ s00253-012-4518-x

14. Bao F, Wang L, Zhao X, et al. Preparation and characterization of a single-domain antibody specific for the porcine epidemic diarrhea virus spike protein. AMB Express. 2019;9(1):104. doi:10.1186/s13568-019-0834-1

15. Bailon Calderon H, Yaniro Coronel VO, Cáceres Rey OA, et al. Development of nanobodies against hemorrhagic and myotoxic components of Bothrops atrox snake venom. Front Immunol. 2020;11:655. doi:10.3389/fimmu.2020.00655

16. Kovaleva M, Ferguson L, Steven J, Porter A, Barelle C. Shark variable new antigen receptor biologics - a novel technology platform for therapeutic drug development. Expert Opin Biol Ther. 2014;14(10):1527-1539. doi:10.1517/14712598.2014.937701 
17. Müller MR, Saunders K, Grace C, et al. Improving the pharmacokinetic properties of biologics by fusion to an anti-HSA shark VNAR domain. MAbs. 2012;4(6):673-685. doi:10.4161/mabs.22242

18. Grzeschik J, Könning D, Hinz SC, et al. Generation of semi-synthetic shark IgNAR single-domain antibody libraries. Methods Mol Biol. 2018;1701:147-167.

19. Vandenbroucke K, de Haard H, Beirnaert E, et al. Orally administered L. lactis secreting an anti-TNF nanobody demonstrate efficacy in chronic colitis. Mucosal Immunol. 2010;3(1):49-56. doi:10.1038/mi.2009.116

20. Danquah W, Meyer-Schwesinger C, Rissiek B, et al. Nanobodies that block gating of the P2X7 ion channel ameliorate inflammation. Sci Transl Med. 2016;8(366):366ra162. doi:10.1126/scitranslmed.aaf8463

21. Rissiek B, Koch-Nolte F, Magnus T. Nanobodies as modulators of inflammation: potential applications for acute brain injury. Front Cell Neurosci. 2014;8:344. doi:10.3389/fncel.2014.00344

22. Dooley H, Flajnik MF, Porter AJ. Selection and characterization of naturally occurring single-domain (IgNAR) antibody fragments from immunized sharks by phage display. Mol Immunol. 2003;40:25-33. doi:10.1016/S0161-5890(03)00084-1

23. Xia Y, Zhao G, Lin J, et al. 1,25(OH)2D3 and VDR signaling pathways regulate the inhibition of Dectin-1 caused by Cyclosporine A in response to aspergillus fumigatus in human corneal epithelial cells. PLoS One. 2016;11(10):e0164717. doi:10.1371/journal.pone.0164717

24. Wu TG, Wilhelmus KR, Mitchell BM. Experimental keratomycosis in a mouse model. Invest Ophthalmol Vis Sci. 2003;44(1):210-216. doi:10.1167/iovs.02-0446

25. Xia L, Teng Q, Chen Q, Zhang F. Preparation and characterization of anti-GPC3 nanobody against hepatocellular carcinoma. Int J Nanomedicine. 2020;15:2197-2205. doi:10.2147/IJN.S235058

26. Gu L, Lin J, Wang Q, et al. Dimethyl itaconate protects against fungal keratitis by activating the Nrf2/HO-1 signaling pathway. Immunol Cell Biol. 2020;98(3):229-241. doi:10.1111/imcb.12316

27. Jiang N, Zhao G, Lin J, et al. Indoleamine 2,3-dioxygenase is involved in the inflammation response of corneal epithelial cells to aspergillus fumigatus infections. PLoS One. 2015;10(9):e0137423. doi:10.1371/journal.pone.0137423

28. Liu X, You J, Peng X, et al. Mammalian Ste20-like kinase 4 inhibits the inflammatory response in Aspergillus fumigatus keratitis. Int Immunopharmacol. 2020;88:107021. doi:10.1016/j.intimp.2020.107021

29. Huang X, Liu X, Peng X, et al. Production of egg yolk antibody against A.fumigatus and its therapeutic potential for treating A.fumigatus keratitis. Microb Pathog. 2021;158:105081. doi:10.1016/j.micpath.2021.105081

30. Zhu Y, Peng X, Zhang Y, Lin J, Zhao G. Baicalein protects against aspergillus fumigatus keratitis by reducing fungal load and inhibiting TSLP-induced inflammatory response. Invest Ophthalmol Vis Sci. 2021;62(6):26. doi:10.1167/iovs.62.6.26

31. Niu Y, Lin J, Li C, et al. Galectin-3 plays an important pro-inflammatory role in A. fumigatus keratitis by recruiting neutrophils and activating p38 in neutrophils. Int Immunopharmacol. 2021;97:107706. doi:10.1016/j.intimp.2021.107706

32. Tian X, Peng X, Lin J, et al. Isorhamnetin ameliorates aspergillus fumigatus keratitis by reducing fungal load, Inhibiting pattern-recognition receptors and inflammatory cytokines. Invest Ophthalmol Vis Sci. 2021;62(3):38. doi:10.1167/iovs.62.3.38

33. Yin J, Peng X, Lin J, et al. Quercetin amelioratesAspergillus fumigatuskeratitis by inhibiting fungal growth, toll-like receptors and inflammatory cytokines. Int Immunopharmacol. 2021;93:107435. doi:10.1016/j.intimp.2021.107435

34. Zhan L, Peng X, Lin J, et al. Honokiol reduces fungal load, toll-like receptor-2, and inflammatory cytokines in Aspergillus fumigatus keratitis. Invest Ophthalmol Vis Sci. 2020;61(4):48. doi:10.1167/iovs.61.4.48

35. Ye G, Gallant J, Zheng J, et al. The development of Nanosota-1 as anti-SARS-CoV-2 nanobody drug candidates. Elife. $2021 ; 10: e 64815$. doi:10.7554/eLife.64815

36. Li L, Zhu Y, Liu M, et al. Conjugation of oxaliplatin with PEGylated-nanobody for enhancing tumor targeting and prolonging circulation. $J$ Inorg Biochem. 2021;223:111553. doi:10.1016/j.jinorgbio.2021.111553

37. Zhang Q, Wu L, Liu S, et al. Moderating hypoxia and promoting immunogenic photodynamic therapy by HER-2 nanobody conjugate nanoparticles for ovarian cancer treatment. Nanotechnology. 2021;32(42):425101. doi:10.1088/1361-6528/ac07d1

38. Weng D, Yin ZF, Chen SS, et al. Development and assessment of the efficacy and safety of human lung-targeting liposomal methylprednisolone crosslinked with nanobody. Drug Deliv. 2021;28(1):1419-1431. doi:10.1080/10717544.2021.1921073

39. Gow NA, Netea MG, Munro CA, et al. Immune recognition of candida albicans $\beta$-glucan by Dectin-1. J Infect Dis. 2007;196(10):1565-1571. doi:10.1086/523110

40. Zhong J, Huang W, Deng Q, et al. Inhibition of TREM-1 and Dectin-1 alleviates the severity of fungal keratitis by modulating innate immune responses. PLoS One. 2016;11:e150114. doi:10.1371/journal.pone.0150114

41. Sokullu E, Gauthier MS, Coulombe B. Discovery of antivirals using phage display. Viruses. 2021;13(6):1120. doi:10.3390/v13061120

42. Moeglin E, Desplancq D, Stoessel A, et al. A novel nanobody precisely visualizes phosphorylated histone H2AX in living cancer cells under drug-induced replication stress. Cancers. 2021;13(13):3317. doi:10.3390/cancers13133317

43. Ákos Z, Dunipace L, Stathopoulos A. NaNuTrap, a technique for in vivo cell nucleus labelling using nanobodies. Development. 2021;148: dev199822. doi:10.1242/dev.199822

44. Wagner TR, Ostertag E, Kaiser PD, et al. NeutrobodyPlex-monitoring SARS-CoV-2 neutralizing immune responses using nanobodies. EMBO Rep. 2021;22(5):e52325. doi:10.15252/embr.202052325

45. Zhang W, Lin M, Yan Q, et al. An intracellular nanobody targeting T4SS effector inhibits Ehrlichia infection. Proc Natl Acad Sci U S A. 2021;118 (18):e2024102118. doi:10.1073/pnas.2024102118

46. Papp KA, Weinberg MA, Morris A, Reich K. IL17A/F nanobody sonelokimab in patients with plaque psoriasis: a multicentre, randomised, placebo-controlled, phase 2b study. Lancet. 2021;397(10284):1564-1575. doi:10.1016/S0140-6736(21)00440-2

47. Liao S, Liu S, Zhang Y. Preparation of anti toll-like receptor-4 nano-antibody and Its effect on gram negative sepsis. $J$ Nanosci Nanotechnol. 2021;21(2):1048-1053. doi:10.1166/jnn.2021.18664 


\section{Publish your work in this journal}

The International Journal of Nanomedicine is an international, peer-reviewed journal focusing on the application of nanotechnology in diagnostics, therapeutics, and drug delivery systems throughout the biomedical field. This journal is indexed on PubMed Central, MedLine, CAS, SciSearch ${ }^{\circledR}$, Current Contents ${ }^{\mathbb{B}} /$ Clinical Medicine, Journal Citation Reports/Science Edition, EMBase, Scopus and the Elsevier Bibliographic databases. The manuscript management system is completely online and includes a very quick and fair peer-review system, which is all easy to use. Visit http:// www.dovepress.com/testimonials.php to read real quotes from published authors.

Submit your manuscript here: https://www.dovepress.com/international-journal-of-nanomedicine-journal 